\title{
Adult Vaccination and Voluntary Vaccination State of Adults: A Study from Turkey
}

\author{
Melis Naçar ${ }^{1}$, Fevziye Çetinkaya ${ }^{2}$, Zeynep Baykan ${ }^{1}$, Serpil Poyrazoğlu ${ }^{3}$, Osman Günay ${ }^{2}$ \\ ${ }^{1}$ Department of Medical Education, Erciyes University School of Medicine, Kayseri, Turkey; ${ }^{2}$ Department of Public Health, Erciyes \\ University School of Medicine, Kayseri, Turkey; ${ }^{3}$ Physician in Kayseri, Turkey. \\ Email: mnacar@erciyes.edu.tr
}

Received February $15^{\text {th }}, 2011$; revised April $3^{\text {rd }}, 2011$; accepted April $13^{\text {th }}, 2011$.

\begin{abstract}
In this study, establishing the knowledge about adult vaccination and voluntary vaccination state of adults in the province centre of Kayseri was aimed. This descriptive study was performed in 2009 May-July, in 6 public health centres (PHC) in the province centre of Kayseri, by way of a questionnaire. 998 adults from the population of an area covered by 34 family practitioners, working under six public health care centres, in the province centre of Kayseri, were asked to fill a questionnaire. Chi-square test was used in the statistical analysis and $p<0.05$ was accepted as significant. The mean age of the participants was $37.4 \pm 14.1$ and $56.7 \%$ were female. $75.8 \%$ of the individuals knew that adults had to be vaccinated and $55.3 \%$ that influenza vaccination had to be done every year. $97.9 \%$ of the participants were aware of influenza vaccinLation, and the rate of vaccination was 7.8\%, 97.8\% knew tetanus vaccination, the awareness rate of hepatitis B vaccination was $84.4 \%$, and vaccination rate $25.6 \%$, Human Papilloma Virus (HPV) was known by $44.4 \%$, vaccination rate in women was $1.1 \%$, pneumococcus vaccination was known by $19.8 \%$ and vaccination rate was $0.4 \%$. $22.0 \%$ of the individuals 65 years old and above had got an influenza vaccination while non-had got a pneumococcus vaccination. It is found that the tetanus, influenza, and hepatitis vaccinations were highly known, whereas, HPV and pneumococcus vaccinations were not, and that the number of individuals stating that they had been vaccinated was quite low.
\end{abstract}

Keywords: Adult Vaccination, Vaccination Status, Voluntary Vaccination, Turkey

\section{Introduction}

Vaccination is among the most important issues within community health, enabling the prevention of preventable diseases and the consequent deaths. Worldwide and in Turkey, there is a growing success in the prevention of disease mortality and morbidity in children, thanks to the increase success in vaccination programs, but unfortunately, adult vaccination is not that widespread [1-5].

According to the "2010 year Healthy People Project" of the World Health Organization (WHO), an effort has to be made in order to decrease diseases preventable by vaccination by increasing vaccination rates in adults. According to this project, influenza and pneumococcus vaccination is aimed to reach to a $90 \%$ coverage rate in adults above 65 years old, and to $60 \%$ in the risk groups [6]. In our country, just as it is in child vaccination, the necessary set up for adult vaccination has to be provided and the guidelines have to be applied. There has not been a national consensus regarding adult vaccination yet, but the Ministry of Health has started some structural arrangements on this topic [7].

Many a suggestion has been proposed in literature regarding adult vaccination. Apart from vaccinations such as hepatitis B, tetanus, pneumococcus, influenza, human papilloma virus (HPV) advised for adults, there are some other vaccinations that can be applied when needed to people under risk. Polio, rabies, meningococcus, typhoid, cholera comprises some of these $[1,8]$.

Beginning from doctors, the lack of knowledge of health personnel, the uncertainties regarding their safety and effectiveness, the preoccupations about their side effects, the fact that they usually are not covered by social security and their expense, are all some of the causes of the low vaccination rates in adults. Apart from all these, the fact that there is no national policy about adult vaccination, and the potential economic cost vaccination can bring to the national budget are additional factors explaining the low rate [9-11]. It was established that, in Australia, the introduction of pneumococcus vaccination 
in elderly into the free routine vaccination program, has caused a dramatic increase in pneumococcus vaccination rates [12].

In this study, establishing the knowledge about adult vaccination and vaccination rates in adults in Kayseri province centre was aimed.

\section{Material and Method}

This descriptive study was performed in 2009 May-July, in 6 public health centres (PHC) in the province centre of Kayseri, by way of a questionnaire. Every 171 family practitioners working under the PHC were accepted as a group, $1 / 5$ th of these groups that means, 34 family practitioners areas were taken as the sample. Taking into account the results from the studies by Dursun and Naçar $[13,14]$, stating that the HPV awareness rate was $45 \%$, and hepatitis B $56.2 \%$, with $\alpha=0.05$, power $=0.80, \beta=$ 0.20 , we required a minimum of 969 participants. By way of quota sampling we took 30 people from each family practitioner's area and performed the questionnaire to a total of 1020 people. Individuals above 18 years old were accepted as adults. People who did not want to participate and the ones with high-grade dementia due to age were not included. 22 questionnaires were left out due to lack of data and 998 people, out of the aimed 1020, were included in the study.

Educated interviewers, on a face-to-face basis, to individuals who had accepted to participate, performed standard questionnaire forms, comprising 41 questions. In this questionnaire aimed to investigate the knowledge, attitude and conduct regarding adult vaccination, descriptive characteristics such as age, gender, and educational status; the presence of risk factors; their thought about the necessity of adult vaccines; knowledge about vaccines and the vaccination states; if they had got a vaccination, how they had been informed about it; if they did not get a vaccination, the reason they didn't; awareness about which vaccination had to be taken in risky situations, were all investigated. First they were asked to state the vaccinations they knew, then, each vaccination was named, asking whether or not they had heard about it.

The SPSS program evaluated the data obtained by the questionnaire. Chi-square test was used in the statistical analysis of the groups, and $p<0.05$ was accepted as significant. Ethical Committee approval was taken.

\section{Results}

The mean age of the participants was $37.4 \pm 14.1$, and $56.7 \%$ were women (Table 1). $75.8 \%$ of our participants were aware that adults had to be vaccinated, $67.3 \%$ that pregnant had to be vaccinated, and $55.3 \%$ influenza vaccination had to be get every year. $49.3 \%$ of the men, and
$81.1 \%$ of the women knew that pregnant should get a tetanus vaccination $(x 2=113.719, \mathrm{p}=0.0001)$.

$22.0 \%$ of the participants are 65 years old and above, and $5.4 \%$ of the caregivers of children below 5 years of age had got an influenza vaccination. $0.9 \%$ of the smokers were vaccinated for pneumococcus, whereas none of the adults above 65 years of age were vaccinated. $72.7 \%$ of the people dealing with blood and blood products, and $31.4 \%$ of the household contacts of chronic hepatitis B patients had been vaccinated for hepatitis $B$.

$95.9 \%$ of the participants knew that they had to get a tetanus vaccination in injuries with rusty nails, $81.6 \%$ when the baby's umbilicus was cut with dirty devices, $62.9 \%$ in car accidents, $32.1 \%$ in animal bites, and $20.2 \%$ in cases of contact with a tetanus patient.

$37.2 \%$ of the participants who had hepatitis B vaccination, $37.3 \%$ who had influenza vaccination, and one out of four who had pneumococcus vaccination, did so, following doctors' advice.

The rate of awareness about HPV vaccination was higher among women than men in our group. Knowledge about tetanus, hepatitis $\mathrm{B}$ and pneumococcus vaccinations was higher in the 25 - 44 age group, and HPV awareness was higher in the $18-24$ age group. Again, awareness about adult vaccination was higher in the group with an education of high school and above, compared to the junior high school and below group (Table 2).

Table 1. Discriptive characteristics of the participants.

\begin{tabular}{|c|c|c|}
\hline Characteristics & Number & $\%$ \\
\hline \multicolumn{3}{|l|}{ Age groups $(n=998)$} \\
\hline $18-24$ & 253 & 24.4 \\
\hline $25-44$ & 492 & 49.3 \\
\hline $45-64$ & 212 & 21.2 \\
\hline $65+$ & 41 & 4.1 \\
\hline \multicolumn{3}{|l|}{ Gender(n = 998) } \\
\hline Female & 566 & 56.7 \\
\hline Male & 432 & 43.3 \\
\hline \multicolumn{3}{|l|}{ Marital status $(n=998)$} \\
\hline Married & 716 & 71.8 \\
\hline Single & 248 & 24.8 \\
\hline Widower/divorced & 34 & 3.4 \\
\hline \multicolumn{3}{|l|}{ Education $(n=998)$} \\
\hline Illiterate & 32 & 3.2 \\
\hline Literate & 28 & 2.8 \\
\hline Primary school & 301 & 30.2 \\
\hline Junior high school & 131 & 13.1 \\
\hline High school & 282 & 28.3 \\
\hline Higher school (university) & 244 & 22.4 \\
\hline
\end{tabular}


Table 2. Knowledge among participants regarding adult vaccination according to their sociodemographic caharacteristics (\%).

\begin{tabular}{|c|c|c|c|c|c|c|}
\hline Characteristics & $\mathbf{n}$ & Tetanus & Hepatitis & Influenza & Pneumococcus & HPV \\
\hline \multicolumn{7}{|l|}{ Gender } \\
\hline Female & 566 & 98.2 & 84.3 & 98.1 & 20.1 & 53.4 \\
\hline Male & 432 & 97.2 & 84.5 & 97.7 & 19.4 & 32.6 \\
\hline$\chi^{2}$ & & 1.162 & 0.009 & 0.164 & 0.075 & 42.602 \\
\hline $\mathrm{p}$ & & 0.281 & 0.926 & 0.685 & 0.784 & 0.0001 \\
\hline \multicolumn{7}{|l|}{ Age groups } \\
\hline $18-24$ & 253 & 98.0 & 86.6 & 97.6 & 19.1 & 52.6 \\
\hline $25-44$ & 492 & 99.2 & 88.0 & 99.0 & 24.8 & 47.2 \\
\hline $45-64$ & 212 & 94.3 & 79.2 & 95.8 & 10.8 & 34.0 \\
\hline $65+$ & 41 & 97.6 & 53.7 & 97.6 & 12.2 & 14.6 \\
\hline$\chi^{2}$ & & 16.235 & 39.404 & 7.655 & 20.003 & 32.424 \\
\hline $\mathrm{p}$ & & 0.001 & 0.0001 & 0.054 & 0.0001 & 0.0001 \\
\hline \multicolumn{7}{|l|}{ Educational status } \\
\hline Junior high school and below & 492 & 96.5 & 78.0 & 96.7 & 11.6 & 37.2 \\
\hline High school and above & 506 & 99.0 & 90.5 & 99.0 & 27.9 & 51.4 \\
\hline$\chi^{2}$ & & 7.043 & 29.390 & 6.206 & 41.573 & 20.343 \\
\hline $\mathrm{p}$ & & 0.008 & 0.0001 & 0.013 & 0.0001 & 0.0001 \\
\hline
\end{tabular}

\section{Discussion and Conclusion}

Although immunization against infectious diseases is a lifelong process, it is not seen as a health issue for adults. Taking into consideration the benefits it brings to the individual and the community, and the costs that preventable diseases can bring to a society, adult vaccination is a very important issue [6]. $75.8 \%$ of our participants believed that adults should be vaccinated. In a similar study performed in America, in 2008, 82\% of the participants' believed that adults should be vaccinated [10].

The first three vaccinations known among our participants were influenza (97.9\%), tetanus $(97.8 \%)$ and hepatitis B (84.4\%). While the awareness rates of these three vaccinations were high, the vaccination rates were low (Table 3). Facts such as, the long-term administration of tetanus vaccination in our country, the widespread characteristic of influenza and hepatitis B diseases, and their being frequently mentioned by mass media, can all be thought of as the reasons for this high awareness. In a study performed in Kayseri in 1999 on women, the awareness rate of hepatitis $\mathrm{B}$ vaccination was $56.2 \%$ [14]. Comparisons with our study results, it shows that the awareness rate of hepatitis $B$ vaccination has increased in the last 10 years.

Cost-effectiveness, and found that vaccination for $\mathrm{HBV}$, is superior to fighting the infection, both in short and long-terms [17]. In our study, although the knowledge rate about hepatitis $\mathrm{B}$ vaccination was high, the
Table 3. The knowledge about adult vaccinations and vaccination state among the participants.

\begin{tabular}{lcccc}
\hline Vaccination $(\mathbf{n}=\mathbf{9 9 8})$ & \multicolumn{2}{c}{$\begin{array}{c}\text { Aware } \\
\text { Number } \\
\text { \% }\end{array}$} & \multicolumn{2}{c}{$\begin{array}{c}\text { Vaccinated } \\
\text { Number } \\
\text { \% }\end{array}$} \\
\hline Influenza vaccination & 977 & 97.9 & 78 & 7.8 \\
Tetanus vaccination & 976 & 97.8 & $*$ & $*$ \\
Hepatitis B vaccination & 842 & 84.4 & 255 & 25.6 \\
HPV vaccination & 443 & 44.4 & 6 & $1.1 * *$ \\
Pneumococcus vaccination & 198 & 19.8 & 4 & 0.4 \\
\hline
\end{tabular}

*The majority of the participants did not remember their tetanus vaccination state within the last ten years; **Percent was taken out of 566 women.

vaccination rate was low (25.6\%). Again in 1999, in a study performed on women in Kayseri, the vaccination coverage rate of hepatitis B was as low as $5.3 \%$ (14). In a study performed in our country, in 2009 , with the highrisk group of women-hairdresser, $37.6 \%$ were vaccinated against hepatitis B [18]. In a study performed in America with the Chinese, the knowledge rate of hepatitis B vaccine was $53.2 \%$, whereas the vaccination rate was low by $31.1 \%$ [19].

Influenza infection causes serious morbidity and mortality in children under two years old, in elder people above 65 years old and in people with chronic diseases. Centre of Disease Control (CDC) Advisory Committee on Immunization Practices suggests influenza vaccination to children between 6 months-18 years old and to all 
adults who are concerned about lowering the risk of infecting other people [20]. $97.9 \%$ of our participants stated that they had heard about influenza vaccination, and $7.8 \%$ stated that they got a vaccination. Among the participants 65 years old and above in our study, the group accepted to be under risk, $22.0 \%$ ( 9 people) had got an influenza vaccination. In a study performed in our country in a group above 65 years old, only $26.8 \%$ had got an influenza vaccination [16], and in another study performed in people above 60 years old this rate was $27.9 \%$ [21].

The low immunity rate for tetanus disease among adults in Turkey is a very important issue needed to be solved $[22,23]$. As most of the participants could not remember their tetanus vaccination coverage, our not being able to give a rate is another limitation of our study. In a study performed in our country with individuals above 65 years old, only two (1.8\%) had got a tetanus vaccination in the last ten years [16]. Tetanus vaccine has to be done every ten years, if not, it has to be done during pregnancy and in cases of injury $[7,24]$. In this study, awareness rates of situations in which tetanus vaccine has to be administered was; after injury with a rusty nail $95.9 \%$, and following car accident $62.9 \%$. Although the necessity for tetanus vaccination after injury with a rusty nail was widely known, its necessity in more important situations, such as car accidents, that can cause more serious consequences in terms of tetanus, is known at lower rates.

The goal WHO has set in 1989 for eliminating neonatal tetanus, has still not been successful in spite of the long years that have elapsed [25]. In order to accomplish elimination, healthy birth conditions and the vaccination of women between 15 - 49 years old with Td have to be implemented. Tetanus immunization in our country is not in the expected level due to lack of knowledge and motivation. The coverage rate is $47 \%$ in women in the fertile period [7]. In our study $67.3 \%$ of the participants knew that pregnant women had to be vaccinated. In the province of Aydin, in a study performed in 2007 in women between ages 15 - 49 [26], 64.1\% of the women stated that they did not have any knowledge about tetanus vaccination.

The establishment of the relationship between HPV and cervical cancer has brought forward the protection with vaccination. This vaccination is suggested to all women less than 26 years of age, who have not been vaccinated $[8,26,27]$. In a study performed in Turkey [13] only $45 \%$ of the women had heard about HPV vaccination and in a study from Australia [28] 83\% of the adults were aware. In our study, $44.4 \%$ of the entire group, $32.6 \%$ of the men, and $53.4 \%$ of the women knew HPV vaccination, and only 4 out of 556 women $(0.4 \%)$ had been vaccinated. Awareness of HPV vaccination was higher in women. In a study performed in Singapore, knowledge of men about HPV vaccination was found to be substantially insufficient [29]. These kinds of investigations are usually performed in women, thus very little is known about the awareness in men. Fathers are as responsible as mothers in getting their daughters vaccinated for HPV. Therefore, educational programs about the topic should comprise men, as well as women.

In our study, the people who dealt with blood and blood products all stated that they knew about hepatitis vaccination, but only $72.7 \%$ had been vaccinated. In a study from our country, $68.4 \%$ of the doctors stated that they had been vaccinated for hepatitis B [30]. It has been shown that the risk of hepatitis $B$ infection increases in household contacts of hepatitis B patients [31]. In our study group, $94.3 \%$ of the individuals living with a patient with chronic hepatitis B stated that they knew about the vaccination, but only $31.4 \%$ had got a vaccination. Education should be given about vaccination for people living with hepatitis B carriers.

Influenza, pneumococcus and tetanus vaccinations are suggested to everyone 65 years old and above $[8,12]$. In our study, $97.6 \%$ of the individuals 65 years old and above had heard about influenza vaccination, but only $22.0 \%$ (9 cases) had got vaccinated. Again, only $12.2 \%$ had heard about pneumococcus vaccination, and none had been vaccinated (Table 4). A study performed in Ankara, in 2004, in individuals 65 years old and above [16], vaccination rate for influenza was $26.8 \%$, for tetanus $1.8 \%$, and none had been vaccinated for pneumococcus. In the same study, none of the participants had any information about pneumococcus and tetanus vaccinations, whereas $25 \%$ had knowledge about influenza vaccination.

One of the ways of increasing vaccination coverage rates in adults is to canalise and inform the society appropriately. There is no doubt that this kind of information has to be given by health personnel, doctors being the first on the list. In United States of America, in a study performed in 2000 , it was established that the HPV vaccination rates were importantly affected by doctors' suggestions [32]. We have found that suggestion rates for vaccinations by doctors or health personnel were very low (Table 5). 37.3\% of the people vaccinated against influenza, $37.2 \%$ of the ones vaccinated against hepatitis $\mathrm{B}$, and $25.0 \%$ of the ones vaccinated against pneumococcus had done so because their doctors had advised them to do so. An important reason for this low rate can be the doctors' lack of knowledge. In a study performed by Önal and friends, in 2008, in medical students grade 4 and 6, from İstanbul University Medical Faculty, the Td vaccination knowledge of doctor candidates was found to 
Table 4. The awareness and vaccination state within the participants under risk.

\begin{tabular}{|c|c|c|c|c|}
\hline \multirow{2}{*}{ Risk Groups } & \multicolumn{2}{|c|}{ Aware } & \multicolumn{2}{|c|}{ Vaccinated } \\
\hline & Number & $\%$ & Number & $\%$ \\
\hline \multicolumn{5}{|l|}{ Adults 65 years old and above $(n=41)$} \\
\hline Influenza & 40 & 97.6 & 9 & 22.0 \\
\hline Pneumococcus & 5 & 12.2 & - & - \\
\hline \multicolumn{5}{|c|}{ People caring for children under 5 years of age $5(n=260)$} \\
\hline Influenza & 253 & 97.3 & 14 & 5.4 \\
\hline \multicolumn{5}{|l|}{ Smokers $(\mathrm{n}=336)$} \\
\hline Pneumococcus & 68 & 20.2 & 3 & 0.9 \\
\hline \multicolumn{5}{|c|}{ People dealing with blood and blood products $(n=33)$} \\
\hline Hepatitis B & 33 & 100.0 & 24 & 72.7 \\
\hline \multicolumn{5}{|c|}{ Household contacts of chronic hepatitis B patients $(n=35)$} \\
\hline Hepatitis B & 33 & 94.3 & 11 & 31.4 \\
\hline
\end{tabular}

Table 5. Influenza, Hepatitis B and Pneumococcus vaccination suggested by (\%).

\begin{tabular}{lcccc}
\multicolumn{1}{c}{ Vaccination } & $\mathrm{n}$ & Doctor & Other health personel & Themselves \\
\hline Influenza & 78 & 37.3 & 19.1 & 43.6 \\
Hepatitis B & 255 & 37.2 & 26.9 & 35.9 \\
Pneumococcus & 4 & 25.0 & 50.0 & 25.0 \\
\hline
\end{tabular}

be intermediate. According to the same study, $75.6 \%$ of the students knew that adult type $\mathrm{Td}$ vaccination was applied to seven years old and above [33]. The education of doctors and health personnel during their study period and with in-service trainings will enable them to educate the community and thus immunization rates can increase. In conclusion, we have found that among the adult vaccines, tetanus, influenza and hepatitis B vaccinations are known at high rates, and pneumococcus and HPV vaccinations are known at low rates, and vaccination coverage rates are quite low in our study group. Also, the individuals under risk do not have enough knowledge, and do not get vaccinated.

Taking into account the very low vaccination coverage rates, it can be said that there is a need for nation-wide regulations regarding vaccination. Success in adult vaccination can be obtained by increasing knowledge in the community in general, by developing national policies, and by enabling doctors and health personnel to suggest vaccination to adults when necessary.

Our limitation of this study is that our research group was consisting of people who attended to family practitioners.

\section{REFERENCES}

[1] L. K. Pickering, C. J. Baker, G. L. Freed, S. A. Gall, S. E. Grogg, G. A. Poland, et al., "Immunization Programs for Infants, Children, Adolescents, and Adults: Clinical Prac- tice Guidelines by the Infectious Diseases Society of America," Clinical Infectious Diseases, Vol. 49, No. 6, 2009, pp. 817-840. doi:10.1086/605430

[2] E. Uskun, S. B. Uskun, M. Uysalgenc and M. Yagiz, "Effectiveness of a Training Intervention on Immunization to Increase Knowledge of Primary Healthcare Workers and Vaccination Coverage Rates," Public Health, Vol. 122, No. 9, September 2008, pp. 949-958. doi:10.1016/j.puhe.2007.10.005

[3] P. Scognamiglio, E. Girardi, M. Fusco, P. Piselli, S. R. Spena, C. Maione, et al., "Lack of Implementation of Hepatitis B Virus (HBV) Vaccination Policy in Household Contacts of HBV Carriers in Italy," BMC Infectious Diseases, Vol. 9, 2009, p. 86 doi:10.1186/1471-2334-9-86

[4] P. R. Blank, A. U. Freiburghaus, M. M. Schwenkglenks, T. D. Szucs and U. Kunze, "Influenza Vaccination Coverage Rates in Austria in 2006/07-A Representative Cross-Sectional Telephone Survey," WMW Wiener Medizinische Wochenschrift, Vol. 158, No. 19-20, 2008, pp. 583-588. doi:10.1007/s10354-008-0582-3

[5] R. M. Merrill and J. D. Beard, "Influenza Vaccination in the United States, 2005-2007," Med Sci Monit, Vol. 15, No. 7, 2009, pp. 92-100.

[6] V. J. Babb and J. Babb, "Pharmacist Involvement in Healthy People 2010," Journal of the American Pharmaceutical Association, Vol. 43, No. 1, 2003, pp. 56-60. doi:10.1331/10865800360467051

[7] Turkish Society for Infectious Diseases and Clinical Microbiology Specialty, "Adult Immunization Guide Book," Turkish Ministry of Health, Ankara, 2009. 
[8] R. K. Zimmerman, D. B. Middleton, I. T. Burns, R. D. Clover and S. R. Kimmel, "Routine Vaccines across the Life Span, 2007," J Fam Pract, Vol. 56 (2 Suppl Vaccines), 2007, S18-37, C1-3.

[9] K. P. High, "Overcoming Barriers to Adult Immunization," Journal of American Osteopathic Association, Vol. 109, No. 6, 2009, pp. 25-28.

[10] D. R. Johnson, K. L. Nichol and K. Lipczynski, "Barriers to Adult Immunization," The American Journal of Medicine, Vol. 121, No. 7, July 2008, pp. 28-35. doi:10.1016/j.amjmed.2008.05.005

[11] S. Kalaça, M. Yalçin and S. Simşek Yavuz, "Missed Opportunities for Tetanus Vaccination in Pregnant Women, and Factors Associated with Seropositivity," Public Health, Vol. 118, No. 5, July 2004, pp. 377-382. doi:10.1016/j.puhe.2003.12.011

[12] R. M. Andrews, M. L. Counahan, G. G. Hogg and P. B. McIntyre, "Effectiveness of a Publicly Funded Pneumococcal Vaccination Program against Invasive Pneumococcal Disease among the Elderly in Victoria, Australia," Vaccine, Vol. 23, No. 2, November 2004, pp. 132-138. doi:10.1016/j.vaccine.2004.06.016

[13] P. Dursun, B. Altuntas, E. Kuscu and A. Ayhan, "Women's Knowledge about Human Papillomavirus and Their Acceptance of HPV Vaccine," Australian and New Zealand Journal of Obstetrics and Gynaecology, Vol. 49, No. 2, April 2009, pp. 202-206. doi:10.1111/j.1479-828X.2009.00947.x

[14] F. Çetinkaya, M. Naçar and Y. Öztürk, "The Knowledge of Adult Women about Hepatitis B and Vaccination against Hepatitis B Virus," Journal of Viral Hepatitis, Vol. 1, 1999, pp. 22-27.

[15] P. V. Targonski and G. A. Poland, "Pneumococcal Vaccination in Adults: Recommendations, Trends, and Prospects," Cleveland Clinic Journal of Medicine, Vol. 74, No. 6, 2007, pp. 401-406. doi:10.3949/ccjm.74.6.401

[16] Y. Zeybek, Ý. Tokalak and S. Boyacıŏglu, "Vaccination in the Sixty-Five and over Age Adults," Turkish Journal of Geriatrics, Vol. 7, No. 3, 2004, pp. 152-154.

[17] H. A. Tu, H. J. Woerdenbag, S. Kane, A. Riewpaiboon, M. Van Hulst and M. J. Postma, "Economic Evaluations of Hepatitis B Vaccination for Developing Countries," Expert Review of Vaccines, Vol. 8, No. 7, July 2009, pp. 907-920. doi:10.1586/erv.09.53

[18] N. Şahin, D. Bilgiç, Ü. Esen, R. Çetinkaya and Z. Tozoğlu, "Determining Knowledge and Practices of Hairdressers and Manicurist-Pedicurist about Hepatitis B," TAF Prev Med Bull, Vol. 8, 2009, pp. 147-154.

[19] G. X. Ma, S. E. Shive, J. I. Toubbeh, Y. Tan and D. Wu, "Knowledge, Attitudes, and Behaviors of Chinese Hepatitis B Screening and Vaccination," American Journal of Health Behavior, Vol. 32, No. 2, April 2008, pp. 178-187.

[20] A. E. Fiore, D. K. Shay, K. Broder, J. K. Iskander, T. M. Uyeki, G. Mootrey, et al., "Prevention and Control of Seasonal Influenza with Vaccines: Recommendations of the Advisory Committee on Immunization Practices (ACIP), 2009," MMWR Recommendation Report, Vol. 58(RR-8), 2009, pp. 1-52.
[21] S. Oncel, O. Turhan, P. H. Huseyin and A. N. Yalcin, "Status of Influenza Vaccination in Patients Presenting to Two Neighbourhood Primary Health Care Clinics in Antalya," Infez Med, Vol. 16, No. 2, June 2008, pp. 74-79.

[22] O. Ergönül, T. Sözen and E. Tekeli, "Immunity to Tetanus among Adults in Turkey," Scandinavian Journal of Infectious Diseases, Vol. 33, No. 10, 2001, pp. 728-730. doi: $10.1080 / 003655401317074491$

[23] A. Öztürk, S. Gökahmetoğlu, F. Erdem and S. Misgüroğlu Alkan, "Tetanus Antitoxin Levels among Adults over 40 Years of Age in Central Anatolia, Turkey," Clinical Microbiology and Infection, Vol. 9, No. 1, January 2003, pp. 33-38. doi:10.1046/j.1469-0691.2003.00469.x

[24] W. Popp, U. Werfel and D. Hansen, "Vaccinations for Adults: Do You Also Ask about Individual Risks?" MMW Fortschr Med, Vol. 151, No. 14, 2009, pp. 23-26.

[25] "Maternal Immunization against Tetanus," http://www.who.int/immunization_monitoring/diseases/ MNTE_initiative/en/index2.html/26.08. 2009

[26] M. Önde, F. Ergin, G. Atasoylu and A. Çubuk, "Missed Opportunities for Tetanus Immunization of 15-49 Year Old Women in Aydin," Journal of Adnan Menderes University Medical Faculty, Vol. 8, No. 1, 2007, pp. 12-18.

[27] A. B. Moscicki, "HPV Vaccines: Today and in the Future," Journal of Adolescent Health, Vol. 43, No. 4, October 2008, pp. S26-S40. doi:10.1016/j.jadohealth.2008.07.010

[28] H. Marshall, P. Ryan, D. Roberton, P. Baghurst, “A Cross-Sectional Survey to Assess Community Attitudes to Introduction of Human Papillomavirus Vaccine," Australian and New Zealand Journal of Public Health, Vol. 31, No. 3, June 2007, pp. 235-242. doi:10.1111/j.1467-842X.2007.00054.X

[29] M. Pitts, A. Smith, S. Croy, A. Lyons, R. Ryall and S. Garland, et al., "Singaporean Men's Knowledge of Cervical Cancer and Human Papillomavirus (HPV) and Their Attitudes towards HPV Vaccination," Vaccine, Vol. 27, Ni, 22, May 2009, pp. 2989-2993.

doi:10.1016/j.vaccine.2009.02.101

[30] E. Uzun, Z. F. Akçam, E. Zengin, A. N. Kişioğlu and G. S. Yayl1, "Evaluation of the Hepatitis B infection status, knowledge and behaviours of the research assistants of Suleyman Demirel University School of Medicine," Journal of Suleyman Demirel University Medical Faculty, Vol. 15, 2008, pp. 22-27.

[31] D. Zamir, C. Zamir and S. Rishpon, "Epidemiology of Hepatitis B Virus Infection among Family Members of Chronic Carriers in Israel," Israel Medical Association Journal, Vol. 3, 2001, pp. 338-340.

[32] G. D. Zimet, R. M. Mays, Y. Winston, R. Kee, J. Dickes and L. Su, "Acceptability of Human Papillomavirus Immunization," Womens Health Gend Based Med, Vol. 9, No. 1, July 2000, pp. 47-50. doi: $10.1089 / 152460900318957$

[33] E. Önal, S. Özel, S. Erbil and Ö. Ayvaz, "Knowledge Level of $4^{\text {th }}$ and $6^{\text {th }}$ Grade Medical School Students about Adult Tetanus and Diphtheria Vaccines," Nobel Medicus, Vol. 4, 2008, pp. 27-31. 